Check for updates

Cite this: RSC Adv., 2017, 7, 25673

Received 17th March 2017

Accepted 9th May 2017

DOI: $10.1039 / \mathrm{c} 7 \mathrm{ra03184j}$

rsc.li/rsc-advances

\section{Naphthalimide-based fluorescent gelator for construction of both organogels and stimuli- responsive metallogels $\uparrow$}

\author{
Ao Zhang, Yan Zhang, Zhice Xu, ${ }^{*}$ Yajuan Li, (D) Xudong Yu (D)* and Lijun Geng \\ A new kind of naphthalimide-based gelator NP containing terpyridine group was designed and \\ characterized. NPs can form both organogels and metallogels in 2-methoxyethanol via different gelation \\ approaches. It was also found that the $\mathrm{NP} / \mathrm{Cd}(\mathrm{OAc})_{2}$ metallogel showed multiple stimuli-responsive \\ properties such as heat, $\mathrm{Na}_{2} \mathrm{~S}$ and shear stress with reversible phase changes.
}

\section{Introduction}

In the past two decades, design and synthesis of low molecular weight gelators is of increasing interest due to their potential applications in catalysis, biochemistry, tissue engineering, pollutant removal and sensing materials. ${ }^{1-9}$ Organic compounds are found efficient gelators in organic solvents or water due to the dedicate and synergetic intermolecular interactions including hydrogen bonding, hydrophobic and $\pi-\pi$ stacking interaction. For example, Ajayaghosh et al. report many kinds of $\pi$ organogelators with distinct optical properties; $;^{10}$ D. K. Smith demonstrates a series of 1,3:2,4-dibenzylidene-D-sorbitol (DBS) organolator with varies applications such as pollutant removal and gel electrolytes; ${ }^{11}$ Lu and Xue synthesize the carbazole-based $\pi$ conjugated gelator for vapor sensing. ${ }^{12}$ Fan designs a series of stimuli-responsive dendritic organogels. ${ }^{13}$

Recently, using metal complexes to control molecular assembly is also a well-recognized strategy for constructing gels, in which the facile and dynamic metal-ligand coordination interaction endows the gel with unique and new properties such as enhanced catalytic performance, luminescence, as well as selective and sensitive sensing. ${ }^{14-18}$ For example, Bhattacharjee et al. synthesize a novel copper-based hydrogel for chemical fixation of $\mathrm{CO}_{2} ;{ }^{19} \mathrm{Zhang}$ develops metallogel-base arrays to sense ions and anions with high sensitivity and selectivity; ${ }^{20}$ Liu presents L-histidine based metallogel with dual self-healing and shrinkage properties.$^{21}$ However, to date, it is still difficult to predict the gelation or crystallization process based on molecular structures, and the gelators that

Hebei Research Center of Pharmaceutical and Chemical Engineering, College of Chemical Engineering, Hebei University of Science and Technology, Yuhua Road, 70, Shijiazhuang 050080, PR China.E-mail: chemyxd@163.com

$\dagger$ Electronic supplementary information (ESI) available: Details of experiment section, additional spectra and images. See DOI: $10.1039 / \mathrm{c} 7 \mathrm{ra03184j}$ can both form organogels and metallogels have been scarcely reported.

In previous works, we also designed many naphthalimidebased organogelator that can form functional organogels and hydrogels containing cholesterol and sugar groups respectively. ${ }^{22-24}$ In consideration of the synthesis of fluorescent gelator that can form both organogels and metallogels, terpyridine group was introduced in to the naphthalimide backbone, a novel gelator NP was designed and characterized, which contained amide group as hydrogen bonding sites, naphthalimide unit as $\pi$ segment, and terpyridine group for binding with metal ions. We anticipated that the binding of terpyridine with metal ions could change the gelation pathway via coordination interaction and other cooperatively noncovalent interactions, for example, easy gel formation just at room temperature rather than heating-cooling process or ultrasound treatment, leading to novel functions such as multiple stimuli-responsive properties. As expected, NP can form opaque gel in organic solvents such as 1,4-dioxane, 2methoxyethanol, and THF via the heating-cooling process followed by sonication. In the presence of $\mathrm{Cd}(\mathrm{OAc})_{2}$ or $\mathrm{Cu}(\mathrm{OAc})_{2}$, room temperature gelation of $\mathbf{N P}$ was observed just by staying for minutes or shaking-rest (Scheme 1). Further study showed that $\mathbf{N P} / \mathrm{Cd}(\mathrm{OAc})_{2}$ metallogel exhibited thioxtropic properties and could be responsive to heat and $\mathrm{Na}_{2} \mathrm{~S}$ reversibly. This work provide a new strategy to the design of gelators with different gelation pathways tuned by multiple stimuli such as heat, ultrasound and ions.

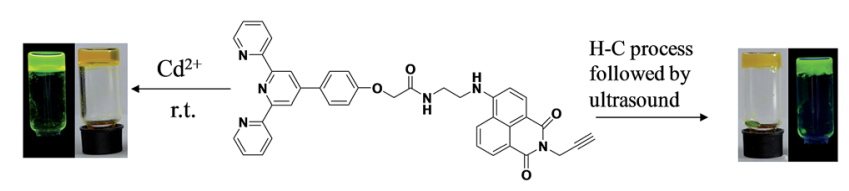

Scheme 1 The chemical structures of NP, photos of NP gel and NP/ $\mathrm{Cd}(\mathrm{OAc})_{2}$ metallogel. 


\section{Experimental}

Materials

All starting materials were obtained from commercial supplies and used without further purification. 4-Vinyl pyridine, 4-bromobenzaldehyde, $\mathrm{Cu}(\mathrm{OAc})_{2}$, 4-Br-1,8-naphthalic anhydride, phenyl isothiocyanate and other reagents were supplied from Shanghai Darui Fine Chemical Co. Ltd.

\section{Techniques}

IR spectra were recorded by using an IRPRESTIGE-21 spectrometer (Shimadzu). SEM images of the xerogels were carried out by using SSX-550 (Shimadzu) and FE-SEM S-4800 (Hitachi) instruments. Samples were prepared by spinning the gels on glass slides and coating them with Au. NMR spectra were performed on a Bruker Advance DRX 400 spectrometer operating at 500 and $125 \mathrm{MHz}$ for ${ }^{1} \mathrm{H}$ NMR and ${ }^{13} \mathrm{C}$ NMR spectroscopy, respectively. Fluorescence spectra were collected on an Edinburgh instrument FLS-920 spectrometer with a Xe lamp as an excitation source. The X-ray diffraction pattern (XRD) was generated by using a Bruker AXS D8 instrument ( $\mathrm{Cu}$ target; $\lambda=$ $0.1542 \mathrm{~nm}$ ) with a power of $40 \mathrm{kV}$ and $50 \mathrm{~mA}$. UV-vis absorption and fluorescent spectra were recorded on a UV-vis 2550 spectroscope (Shimadzu). Sonication treatment of a sol was performed in a KQ-500DB ultrasonic cleaner (maximum power, $100 \mathrm{~W}, 40 \mathrm{kHz}$, Kunshan Ultrasound Instrument Co., Ltd., China).

\section{Results and discussion}

The synthesis and characterization of NP could be seen from ESI. $\dagger$ The gelation test was carried out in a tube by tube inversion method. ${ }^{24}$ From Table $\mathrm{S} 1, \dagger$ by heating-cooling process, no gels were observed. Whereas, stable and yellow emissive gels could be formed when the heated solution was subjected to ultrasound at room temperature in the solvents of butanol, 1,4dioxane, THF and 2-methoxyethanol. Due to the coordination nature of terpyridine group with metal ions, we also tested the assembly properties of NP in the presence of metal ions (Table $\mathrm{S} 2 \dagger)$. The formed metallogels in 2-methoxyethanol by heatingcooling process showed tunable colors (Fig. S1†). For example, the metallogels of NP with $\mathrm{Cu}(\mathrm{OAc})_{2}, \mathrm{FeCl}_{2}$, and $\mathrm{Cd}(\mathrm{OAc})_{2}$ exhibited green, red and yellow color respectively. The counter anions also had obvious impact on the gel colors. For example, in contrast to that of $\mathbf{N P} / \mathrm{Cu}(\mathrm{OAc})_{2}$ metallogel, the $\mathbf{N P} / \mathrm{CuSO}_{4}$ metallogel showed brown earth color. Such color tunable gels might be found potential application in special ion salts sensing.

Notably, $\mathbf{N P} / \mathrm{Cd}(\mathrm{OAc})_{2}$ metallogel (with molecular ratio of 1:1) can form stable and thioxtropic gels just at room temperature by staying or shaking-rest method, indicating the spontaneous coordination interaction between NP and $\mathrm{Cd}(\mathrm{OAc})_{2}$, and such coordination interaction was certified by ${ }^{1} \mathrm{H}$ NMR experiment (Fig. S2 $\dagger$ ). By heating the gel, it became to a sol, which reverted to a gel again after cooling. The above results suggested the tunable gelation approaches of NP in 2-
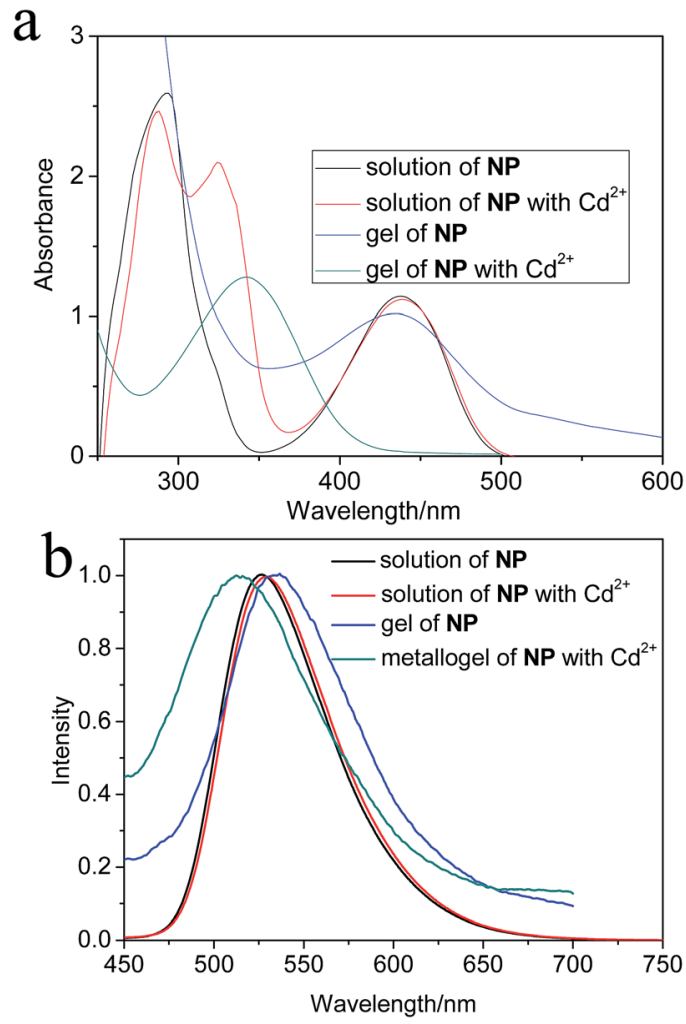

Fig. 1 (a) UV-vis spectra of NP solutions $\left(10^{-4} \mathrm{M}\right)$, gel $\left(25 \mathrm{mg} \mathrm{mL}^{-1}\right)$, and $\mathrm{NP} / \mathrm{Cd}(\mathrm{OAc})_{2}$ metallogel $\left(25 \mathrm{mg} \mathrm{mL}^{-1}\right.$, with molecular ratio of $\mathrm{NP}$ and $\left.\mathrm{Cd}(\mathrm{OAc})_{2}=1: 1\right)$; (b) corresponding fluorescence spectra of NP solutions, gel, and $\mathrm{NP} / \mathrm{Cd}(\mathrm{OAc})_{2}$ metallogel.

methoxyethanol triggered by multiple stimuli such as heating, shaking and ultrasound.

UV-vis and fluorescent studies of both solutions and gels were performed to examine the aggregation changes. From Fig. 1a, the organogel NP and the solutions all showed broad peak at $440 \mathrm{~nm}$ and $293 \mathrm{~nm}$, which was attributed to the ICT process of 4-naphthalimide and pyridyl segments respectively. The peak of NP/Cd(OAc $)_{2}$ metallogel blue shifted from $440 \mathrm{~nm}$ to $342 \mathrm{~nm}$ in comparison to that of the diluted solution, indicating the $\mathrm{H}$ aggregation mode of fluorophores. In contrast to the $\mathrm{NP} / \mathrm{Cu}(\mathrm{OAc})_{2}$ metallogel, there was no obvious spectral changes in UV-vis spectra (Fig. S3†).

In diluted solution state, both the solution of NP and NP/ $\mathrm{Cd}(\mathrm{OAc})_{2}$ aggregates diluted from the metallogel showed maximum emission peak at $527 \mathrm{~nm}$; while, in contrast to the emission peak of the solution, the organogel displayed $9 \mathrm{~nm}$ red shift, and $14 \mathrm{~nm}$ blue shift were observed in the metallogel (Fig. 1b). The $\mathbf{N P} / \mathrm{Cu}(\mathrm{OAc})_{2}$ metallogel also had the same maximum emission peak banded at $541 \mathrm{~nm}$ as that of $\mathrm{NP} /$ $\mathrm{Cd}(\mathrm{OAc})_{2}$ metallogel. As an typical example, the temperature dependent fluorescent changes of $\mathbf{N P} / \mathrm{Cd}(\mathrm{OAc})_{2}$ metallogel were studied. In Fig. 2, by heating the gel from 0 to $90{ }^{\circ} \mathrm{C}$, gel-to-sol transition happened, together with obvious fluorescent quenching with a factor of 3.3. The result revealed that $\pi-\pi$ stacking of NP played an important role for the aggregates in the metallogels. The fluorescent titrations of NP $\left(10^{-5} \mathrm{M}\right)$ with 


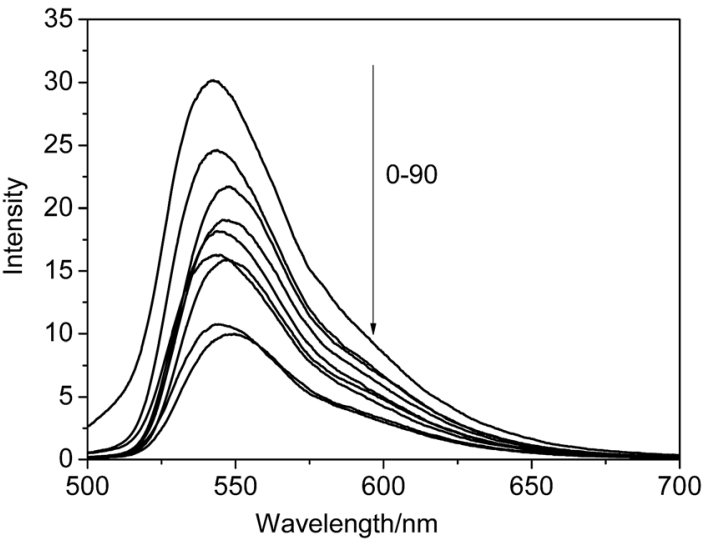

Fig. 2 Temperature dependent fluorescent changes of $\mathrm{NP} / \mathrm{Cu}(\mathrm{OAc})_{2}$ metallogel. Unit for $0-90:{ }^{\circ} \mathrm{C}$.

metal ions were also studied. Addition of $\mathrm{Cd}(\mathrm{OAc})_{2}$ caused remarkable fluorescence enhancement of NP due to the efficient charge transfer from terpyridine group to $\mathrm{Cd}^{2+}$ (Fig. 3a). While, in the presence of $\mathrm{Cu}^{2+}$ or $\mathrm{Fe}^{2+}$ ion, fluorescent quenching was observed (Fig. $3 \mathrm{~b}$ and $\mathrm{S} 4 \dagger$ ). The method of continuous variation (job plot experiments of NP with $\mathrm{Cd}^{2+}$ ) in fluorescent intensity changes revealed a $1: 1$ stoichiometry of NP with $\mathrm{Cd}^{2+}$ (Fig. S5 $\dagger$ ). The corresponding UV-vis titration of NP with ions could be also seen from Fig. S6, $\uparrow$ it was observed that NP showed no selectivity toward ions. The above results indicated that the coordination interaction between NP and $\mathrm{Cd}(\mathrm{OAc})_{2}$ had highly impact on both the ICT process and aggregate mode of NP molecules.

SEM experiments were also examined to check the macrochanges of NP aggregates. The NP gel from 2-methoxyethanol and 1,4-dioxane was comprised of densely entangled nanofibers (Fig. 4a, b and S7†). Porous structure were observed in the NP gel in butanol (Fig. S8 $\dagger$ ). In the presence of $\mathrm{Cd}(\mathrm{OAc})_{2}$, the as prepared gel showed sphere structure in which spheres were linked by short nanofibers (Fig. $4 \mathrm{c}$ and d). The $\mathbf{N P} / \mathrm{FeCl}_{2}$ and $\mathbf{N P} /$ $\mathrm{CaCl}_{2}$ metallogels exhibited ribbon and ellipse structure respectively (Fig. S9 and $\mathrm{S} 10 \dagger$ ). The $\mathrm{NP} / \mathrm{Cu}(\mathrm{OAc})_{2}$ metallogel was dominated by very thin nanofibers with diameter of $20 \mathrm{~nm}$ (Fig. S11†). Interestingly, ion coordination induced supramolecular chirality from achiral components in gel system was observed. Seen from Fig. 5, the organogel and $\mathrm{NP} / \mathrm{Cu}(\mathrm{OAc})_{2}$ metallogel showed no $\mathrm{CD}$ signals. Whereas, the $\mathrm{NP} / \mathrm{Cu}(\mathrm{OAc})_{2}$
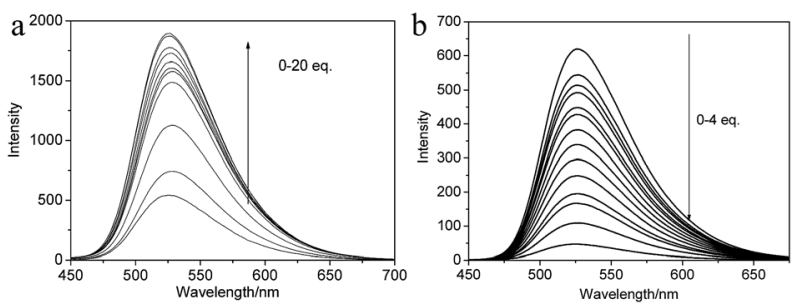

Fig. 3 Fluorescent titrations of NP $\left(10^{-5} \mathrm{M}\right)$ solution upon the addition of metal salts; (a) upon the addition of $\mathrm{Cd}(\mathrm{OAc})_{2}$; (b) upon the addition of $\mathrm{Cu}(\mathrm{OAc})_{2}$.
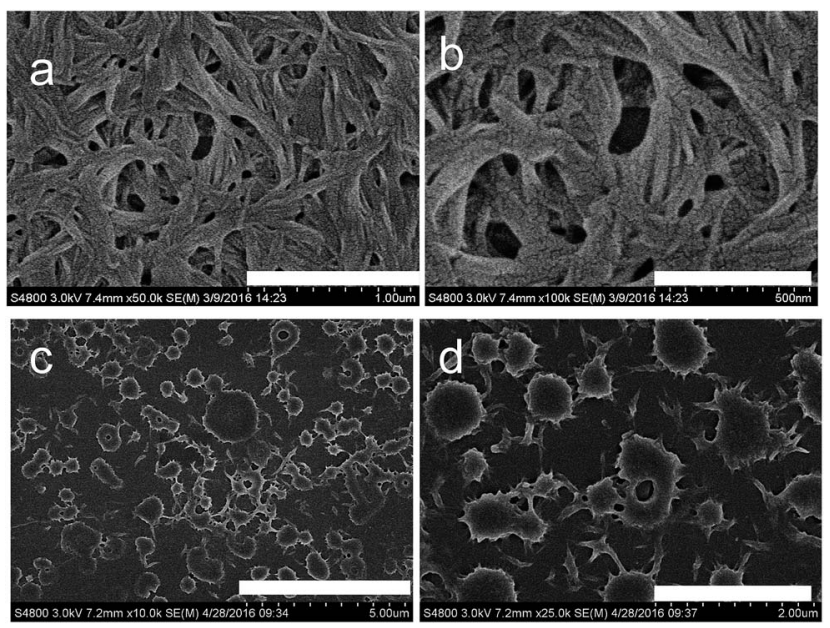

Fig. 4 SEM images of the xerogels. (a) NP xerogel from 2-methoxyethanol; (b) was the magnification picture of (a); (c) NP/Cd(OAc) metallogel; (d) was the magnification spectra of (c). Scale bar: $1 \mu \mathrm{m}$; (b) $500 \mathrm{~nm}$; (c) $5 \mu \mathrm{m}$; (d) $2 \mu \mathrm{m}$.

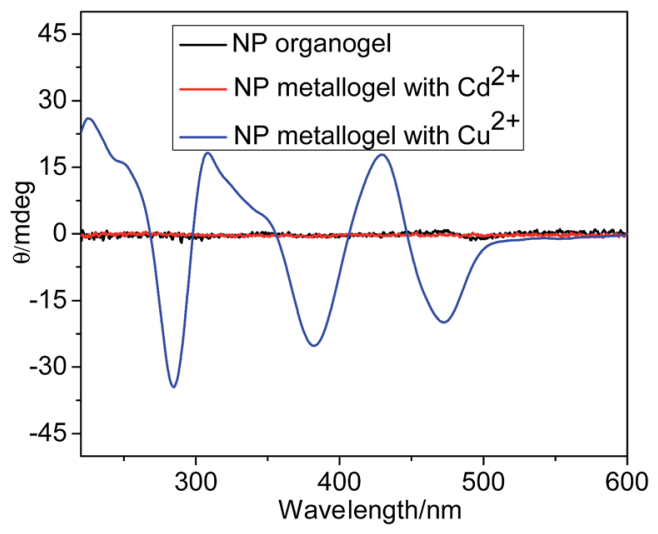

Fig. 5 CD spectra of NP organogel and metallogels.

metallogel of exhibited three positive peaks at $225,307,429 \mathrm{~nm}$ and three negative peaks at 284, 382, $473 \mathrm{~nm}$, which might be resulted from the symmetry breaking of chiral assembly of terpyridine and naphthalimide units. XRD experiments were also studied to examine the different aggregation mode of organogel and metallogel. Seen from Fig. S12, $\uparrow$ the peak of NP organogel positioned at $3.3 \mathrm{~nm}$ was closed to twice the length of a single molecule, indicating the dimer structure. The $d$ value of $2.1 \mathrm{~nm}$ from the $\mathrm{NP} / \mathrm{Cd}(\mathrm{OAc})_{2}$ was rationally ascribed to the length of $\mathbf{N P}$ with $\mathrm{Cd}(\mathrm{OAc})_{2}$.

The $\mathrm{NP} / \mathrm{Cd}(\mathrm{OAc})_{2}$ metallogel could also response to both chemical and physical stimuli such as $\mathrm{Na}_{2} \mathrm{~S}$ and shaking with reversible phase changes. When coating $\mathrm{Na}_{2} \mathrm{~S}$ on the gel surface, the gel became red gradually and finally collapsed (Fig. $\mathrm{S} 13 \dagger$ ). The gel phase could be reversed by further addition of $\mathrm{AgNO}_{3}$. Notably, the color changes were irreversible, and the mechanism was unclear. Moreover, by shaking the gels, the gel transformed to a sol, and it could be reformed by staying for minutes, indicating the thioxtropic properties of the metallogel. To further check the thioxtropic properties of the $\mathrm{NP} / \mathrm{Cd}(\mathrm{OAc})_{2}$ 


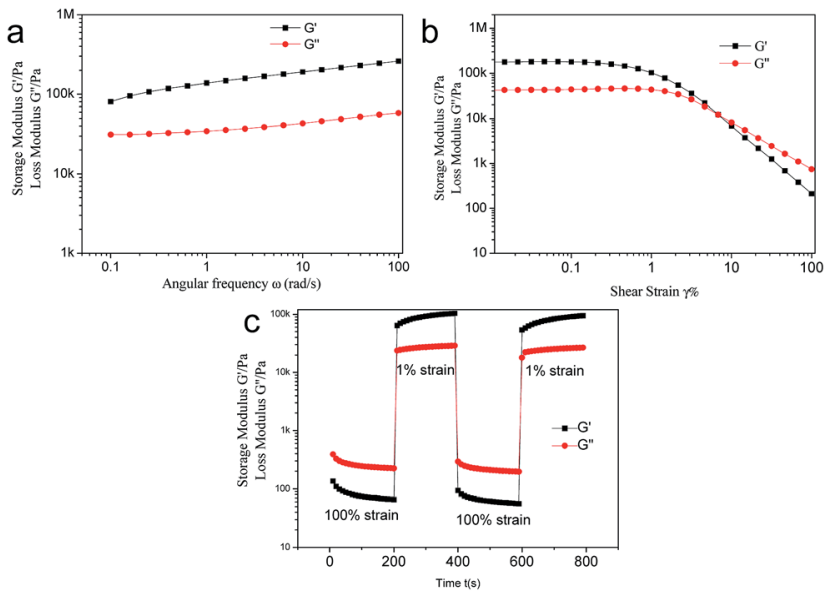

Fig. 6 (a) Frequency measurements of $G^{\prime}$ and $G^{\prime \prime}$ for $\mathrm{NP} / \mathrm{Cd}(\mathrm{OAc})_{2}$ metallogel with strain at $0.1 \%$; (b) strain sweep experiment of NP/ $\mathrm{Cd}(\mathrm{OAc})_{2}$ metallogel with angular frequency of $10 \mathrm{rad} \mathrm{s}^{-1}$; (c) recovery test for $\mathrm{NP} / \mathrm{Cd}(\mathrm{OAc})_{2}$ metallogel, alternating strain amplitudes of $100 \%$ and $1 \%$.

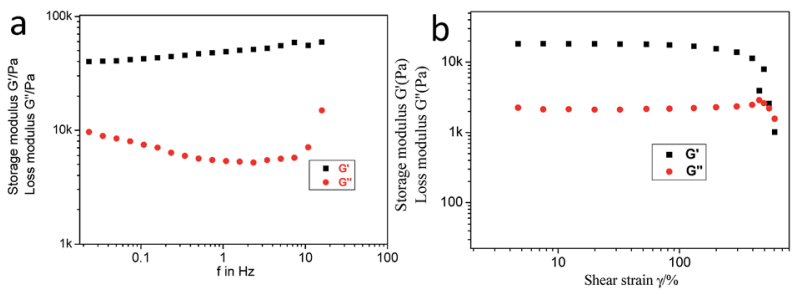

Fig. 7 (a) Frequency measurements of $G^{\prime}$ and $G^{\prime \prime}$ for NP organogel with strain at $0.1 \%$; (b) strain sweep experiment of NP organogel with angular frequency of $10 \mathrm{rad} \mathrm{s}^{-1}$.

metallogel, rheological experiments were studied. From the static frequency measurements, the storage modulus of metallogel $\left(G^{\prime}\right)$ was much higher than that of the loss modulus $\left(G^{\prime \prime}\right)$, which was in accordance with the gel state (Fig. 6a). Fig. 6b showed that the gel to sol transition point was at $6.7 \%$ strain. The recovery experiments could be shown in Fig. 6c. The gel became to a sol when exposed to $100 \%$ strain for $200 \mathrm{~s}\left(G^{\prime}<G^{\prime \prime}\right)$; when the strain was decreased to $1 \%$, the gel reformed again within $200 \mathrm{~s}$. The modulus values of NP organogel was much lower than that of the $\mathbf{N P} / \mathrm{Cd}(\mathrm{OAc})_{2}$ metallogel, which revealed that the metal salt might also behave as linkers to cross-linked the assembly, leading to the higher mechanical strength (Fig. 7).

\section{Conclusion}

In conclusion, a novel gelator NP containing terpyridine and naphthalimide fluorophores was designed and characterized, which can form both organogels and metallogels in 2-methoxyethanol. Ultrasound was necessary in the organogel formation process by heating-cooling process. The coordination of NP with ion salts such as $\mathrm{FeCl}_{2}, \mathrm{Cu}(\mathrm{OAc})_{2}$ and $\mathrm{CaCl}_{2}$ can also promote the gelation without ultrasound. Notably, transparent and fluorescent metallogel could be obtained by staying or shaking-rest just at room temperature in the presence of $\mathrm{Cd}(\mathrm{OAc})_{2}$. The $\mathbf{N P} / \mathrm{Cd}(\mathrm{OAc})_{2}$ metallogel exhibited multiple stimuli responsive properties such as heat, $\mathrm{Na}_{2} \mathrm{~S}$, and shearing. This work provided a good paradigm for understanding how the gelation process was controlled by multiple stimuli. Although we and others report many naphthalimide-based gelators, the naphthalimide-based metallogels were still rare. ${ }^{25}$

\section{Acknowledgements}

The authors thank for the financial support by NNSFC (21401040, 21301047), Xiaoli fund SW (2015PT44), Key Foundation of Hebei Province Department of Education Fund (ZD2016059), Natural Science Foundation of Hebei Province (No. B2014208160, B2014208091), Young Talent Plan of Hebei Province and High-level talent project of Hebei Province (2016002014).

\section{Notes and references}

1 C. D. Jones and J. W. Steed, Chem. Soc. Rev., 2016, 45, 65466596.

2 H. Yang, S. Zhang, K. Liu and Y. Fang, RSC Adv., 2016, 6, 109969-109977.

3 D. Mandal, S. Dinda, P. Choudhury and P. K. Das, Langmuir, 2016, 32, 9780-9789.

4 X. H. Cao, N. Zhao, R. H. Li, H. T. Lv, Z. W. Zhang, A. P. Ao and T. Yi, Chem.-Asian J., 2016, 11, 3196-3204.

5 Y. Gao, F. Zhao, Q. Wang, Y. Zhang and B. Xu, Chem. Soc. Rev., 2010, 39, 3425-3433.

6 W. Zheng, L. J. Chen, G. Yang, B. Sun, X. Wang, B. Jiang, G. Q. Yin, L. Zhang, X. P. Li, M. H. Liu, G. S. Chen and H. B. Yang, J. Am. Chem. Soc., 2016, 138, 4927-4937.

7 G. Cravotto and P. Cintas, Chem. Soc. Rev., 2009, 38, 26842697.

8 Q. Pei, Q. Tang, Z. Tan, Z. Lu, L. He and B. Gong, RSC Adv., 2017, 7, 22248-22255.

9 X. Cao, N. Zhao, G. Zou, A. Gao, Q. Ding, G. Zeng and Y. Wu, Soft Matter, 2017, DOI: 10.1039/c7sm00714k.

10 S. S. Babu, V. K. Praveen and A. Ajayaghosh, Chem. Rev., 2014, 114, 1973-2129.

11 B. O. Okesola, V. M. P. Vieira, D. J. Cornwell, N. K. Whitelaw and D. K. Smith, Soft Matter, 2015, 11, 4768-4787.

12 L. Zhai, M. Liu, P. Xue, J. Sun, P. Gong, Z. Zhang, J. Sun and R. Lu, J. Mater. Chem. C, 2016, 4, 7939-7947.

13 Y. Feng, Y. He and Q. Fan, Chem.-Asian J., 2014, 9, 17241750.

14 A. Y.-Y. Tam and V. W.-W. Yam, Chem. Soc. Rev., 2013, 42, 1540-1567.

15 T. Feldner, M. Häring, S. Saha, J. Esquena, R. Banerjee and D. D. Díaz, Chem. Mater., 2016, 28, 3210-3217.

16 B. Jiang, L. Chen, G. Yin, Y. Wang, W. Zheng, L. Xu and H. Yang, Chem. Commun., 2017, 53, 172-175.

17 H. Yao, H. Wu, J. Chang, Q. Lin, T. Wei and Y. Zhang, New J. Chem., 2016, 40, 4940-4944.

18 S. Sarkar, S. Dutta, S. Chakrabarti, P. Bairi and T. Pal, ACS Appl. Mater. Interfaces, 2014, 6, 6308-6316. 
19 C. K. Karan, M. C. Sau and M. Bhattacharjee, Chem. Commun., 2017, 53, 1526-1529.

20 Q. Lin, T. Lu, X. Zhu, T. Wei, H. Li and Y. Zhang, Chem. Sci., 2016, 7, 5341-5346.

21 M. Liu, L. Zhang and T. Wang, Chem. Rev., 2015, 115, 73047397.

22 T. Wang, X. D. Yu, Y. Li, J. Ren and X. Zhen, ACS Appl. Mater. Interfaces, 2017, 9, 13666-13675.
23 X. D. Yu, X. Ge, H. Lan, Y. Li, L. Geng, X. Zhen and T. Yi, ACS Appl. Mater. Interfaces, 2015, 7, 24312-24327.

24 Z. Ma, P. Zhang, X. Yu, H. Lan, Y. Li, D. Xie, J. Li and T. Yi, J. Mater. Chem. B, 2015, 3, 7366-7371.

25 J. I. Lovitt, C. S. Hawes, A. D. Lynes, B. Haffner, M. E. Möbiusc and T. Gunnlaugsson, Inorg. Chem. Front., 2017, 4, 296-308. 